\title{
A influência dos dispositivos portáteis de leitura no design do livro digital
} The influence of portable reading devices on the digital book design

\author{
Maurício Elias Dick \\ Universidade Federal de Santa Catarina, Brazil \\ mauricioedick@gmail.com \\ Berenice Santos Gonçalves \\ Universidade Federal de Santa Catarina, Brazil \\ berenice@cce.ufsc.br
}

\author{
Alice Teresinha Cybis Pereira \\ Universidade Federal de Santa Catarina, Brazil \\ acybis@gmail.com \\ Milton Luiz Horn Vieira \\ Universidade Federal de Santa Catarina, Brazil \\ milton@cce.ufsc.br
}

\begin{abstract}
To be presented, digital books usually require portable reading devices. Given this relationship, understanding their technology is necessary for the proper design of the digital book. So, this article aims to identify the technological characteristics of portable reading devices that influence the digital book design. The study was developed from a literature research and a systematic review. After these procedures, it was inferred that the choice of the technology relies on the main focus of the publication, whether it is interactivity or continuous reading. Furthermore, the technology influences the choice of the digital book format which determines its design possibilities.
\end{abstract}

Keywords: Design; Technology; Digital book; E-reader; Tablet

\section{Introdução}

A difusão da internet e o aprimoramento da tecnologia ampliou o acesso à informação a partir dos meios digitais. Esse desenvolvimento tecnológico propiciou o surgimento de novas plataformas de interação, como os tablets (computadores de mão) e smartphones (celulares multifuncionais), nos quais não se faz mais necessário o uso de um suporte físico fixo, como acontece com os computadores de mesa. Entram em cena dispositivos com telas maiores, sensíveis ao toque, que permitem grande interação, assim como tecnologias que proporcionam conforto para a leitura de textos extensos, como artigos e romances.

Nesse contexto ressurge o livro digital, cujo acesso se popularizou devido a estas recentes inovações tecnológicas, expandindo sua oferta e alterando a maneira como o usuário interage com eles. Segundo Royo (2008), o Design Digital depende da tecnologia para criar sua linguagem e possuir espaços para atuar. Desse modo, a compreensão da tecnologia a ser utilizada é estritamente necessária para o desenvolvimento de um bom projeto de Design, uma vez que é necessário reconhecer quais são as possibilidades e limitações, bem como as potencialidades oferecidas pelo meio.

Dessa forma, este artigo tem por objetivo identificar as características tecnológicas dos dispositivos portáteis de leitura que influenciam no design do livro digital. Assim, buscou-se compreender as peculiaridades das tecnologias empregadas, suas finalidades e limitações.

O estudo desenvolveu-se a partir de uma pesquisa bibliográfica, complementada por uma revisão sistemática de literatura, visando fornecer um conhecimento das pesquisas mais recentes realizadas acerca do tema

\section{O Livro Digital e a Tecnologia}

De modo a compreender a relação entre a tecnologia e o livro digital, é importante em um primeiro momento entender o conceito deste artefato. Em uma definição recente, Flatschart (2014) afirma que o livro digital é um livro que pode ser lido em dispositivos computacionais, contendo normalmente textos e imagens, e, não raro, recursos de multimídia e interatividade.

A partir de uma visão mais técnica, Procópio (2010) propõe a divisão do livro digital em três dimensões. Para ele, o assunto envolve o software leitor, que é o aplicativo que proporciona a leitura do livro; o dispositivo de leitura (suporte físico), que pode ser portátil ou não; e o livro em si, ou seja, o conteúdo.

No que tange o suporte físico, virtualmente qualquer aparelho computacional com uma tela poderia ser usado como um dispositivo de leitura de livros digitais (Gall, 2005), porém, neste artigo, foca-se nos dispositivos portáteis de leitura, os quais são estudados mais detalhadamente a seguir.

\section{A evolução dos dispositivos portáteis de leitura}

O livro digital não é um assunto novo, embora o mercado em si esteja se iniciando nestes últimos anos (Procópio, 2010; Pinsky, 2013). Nesse sentido, a origem de seus suportes específicos para leitura remonta às décadas de 1940 e 1960, ainda que apenas de maneira conceitual (Procópio, 2010; Wilson, 2001). 
Entretanto, apenas durante a década de 1980, foram desenvolvidos alguns dos primeiros dispositivos portáteis de leitura de livros digitais, que obtiveram sucesso limitado devido à ergonomia pobre em termos de conforto de leitura de seus aparelhos e à falta de um canal apropriado de distribuição de conteúdo (Wilson, 2001).

Segundo Wilson (2001), ainda em meados da década de 1990 surgiram suportes com tela sensível ao toque, porém a partir de 1998 foi lançada a segunda geração de dispositivos portáteis de leitura de livros digitais. Além da habilidade de armazenar múltiplos títulos, já presente em seus predecessores, esses novos dispositivos se tornaram multifuncionais e proporcionavam uma experiencia mais confortável por meio de telas coloridas, sensíveis ao toque e com maiores resoluções, além de mimetizar aspectos da metáfora do livro (Wilson, 2001).

Todavia, esses dispositivos portáteis de leitura de livros digitais não obtiveram grande sucesso no mercado, uma vez que eram considerados um tanto quanto difíceis de usar ou ofereciam poucos itens populares para leitura (Rich; Stone, 2008). Além disso, havia incompatibilidade de formatos, o que impossibilitava a leitura de um livro digital criado para um determinado dispositivo em outro diferente (Farbiarz; Nojima, 2003).

A chegada do dispositivo portátil de leitura Kindle da empresa americana Amazon no ano de 2007 - com sua tecnologia de papel eletrônico e grande oferta de conteúdo - e, em 2010, o lançamento do tablet iPad da também americana Apple (Figura 1) - trazendo excelente experiência do usuário alavancaram novamente o mercado (Santos, 2010; Lopes, 2011; Pinsky, 2013).

Desde então, o mercado dos dispositivos portáteis de leitura tem se caracterizado por duas principais vertentes: os dispositivos dedicados (e-readers) - exemplificados pelo Amazon Kindle - e os dispositivos híbridos (tablets, como o Apple iPad), tendo evoluído basicamente em termos tecnológicos. É importante notar que os dispositivos dedicados têm esta nomenclatura em função da sua dedicação principal à leitura de livros digitais, enquanto os dispositivos híbridos são assim chamados devido ao seu caráter multifuncional.
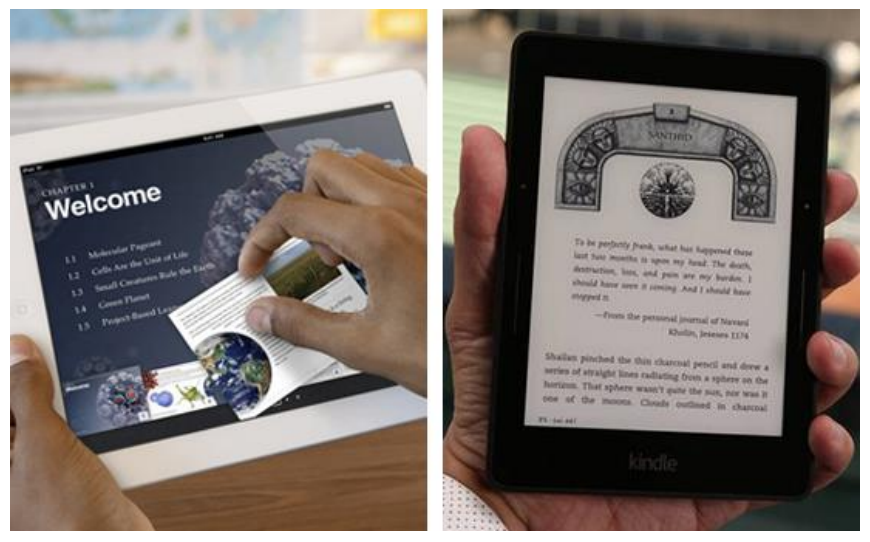

Figura 1: Dois principais tipos de dispositivos portáteis de leitura: híbridos (tablets) e dedicados (e-readers). Fonte: adaptado de Olivarez-Giles (2016) e Ellington (2012).

Sabendo-se, portanto, da existência de diferentes tipos de dispositivos portáteis de leitura, é importante analisar suas tecnologias, uma vez que as características específicas dos dispositivos exigem do designer uma atenção relativa ao suporte (Gruszynski, 2010), sendo necessário que se compreenda seus requisitos e limitações, os quais são fundamentais no momento da projetação do objeto de Design.

\section{As Diferentes Tecnologias e Suas Limitações}

A tecnologia presente nos dois tipos de equipamentos supracitados é claramente distinta. Ainda que haja exceções, a grande maioria dos dispositivos de leitura dedicados se utiliza do papel eletrônico, ou tinta eletrônica, enquanto os dispositivos de leitura híbridos utilizam telas de cristal líquido (LCD), sensíveis ao toque.

\section{Papel eletrônico - dispositivos de leitura dedicados (e-readers)}

Os dispositivos que possuem telas que se utilizam da tecnologia do papel eletrônico têm esse nome por causa da sua aparência de tinta comum sobre o papel. Seu princípio de funcionamento é simples e advém de uma fusão de princípios químicos, físicos e eletrônicos, como afirma a empresa americana Eink (2015), uma das fabricantes da tecnologia. O papel eletrônico é feito de milhões de microcápsulas de tinta preta e branca, as quais possuem cargas elétricas distintas (Strickland, 2008), como mostra a Figura 2.

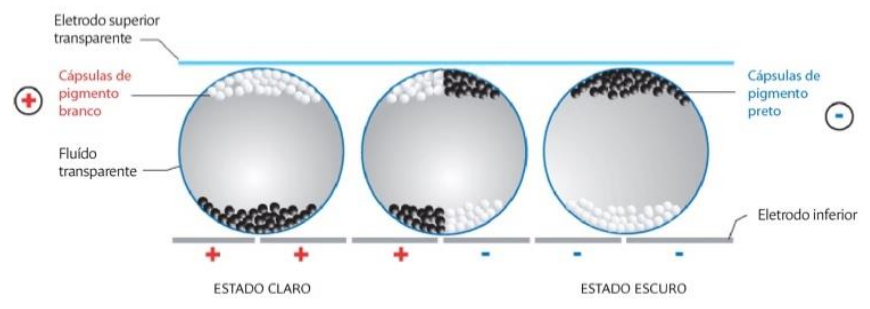

Figura 2: Funcionamento da tecnologia de papel eletrônico. Fonte: adaptado de Eink (2015).

Um conjunto de eletrodos é disposto abaixo do suporte da tela e, segundo Strickland (2008), quando esse conjunto emite uma determinada carga positiva ou negativa, ele repele ou atrai as partículas de tinta, empurrando-as para o topo da microcápsula ou puxando-as para baixo. Ainda, cargas precisas permitem a utilização de diversos tons de cinza. Desta maneira, juntos, centenas de eletrodos e milhares de microcápsulas geram os textos e imagens no papel eletrônico.

Devido a sua maneira de funcionamento, estas telas não utilizam energia elétrica para manter um texto ou imagem, a não ser quando ocorre a mudança da informação mostrada. Sendo assim, a autonomia de bateria destes dispositivos é 
ampla. Além disso, a legibilidade no papel eletrônico é considerada muito boa, uma vez que a informação mostrada é estática (e não atualizada constantemente), o ângulo de visão é grande - devido ao contraste uniforme - e não há emissão de luz própria, somente a reflexão da luz do ambiente (Amazon, 2015).

Por outro lado, os dispositivos de leitura dedicados ainda possuem em sua maioria telas de papel eletrônico monocromáticas - ainda que já existam displays de papel eletrônico coloridos, seu uso ainda não é difundido limitando os aspectos estéticos e ergonômicos de um projeto gráfico. Além disso, apesar de possuírem melhor legibilidade em ambientes muito claros, as telas de papel eletrônico não podem ser lidas em locais sem iluminação, uma vez que esses displays não emitem luz, salvo se o dispositivo possuir luz embutida. Também, alguns dispositivos de leitura dedicados não são sensíveis ao toque, possuindo navegação por manipulação indireta - por meio de botões - dificultando a navegação e a interação do usuário com as ferramentas interativas disponíveis. Outra desvantagem, sob a ótica da interação, é a baixa taxa de atualização da tela, o que impede que sejam executadas interações rápidas ou suaves.

\section{Cristal líquido (LCD) - dispositivos de leitura híbridos (tablets)}

Telas de cristal líquido são utilizadas atualmente em uma grande variedade de dispositivos, tais como televisões, computadores, smartphones, entre outros. O mesmo se aplica à grande maioria dos dispositivos de leitura híbridos (tablets).

Para o funcionamento de uma tela de LCD, é necessária a combinação de quatro fatores: luz polarizada, cristal líquido, corrente elétrica e substâncias transparentes que conduzam eletricidade (Electrónica, 2015). É importante notar, porém, que cristais líquidos não emitem luz. Sua base de iluminação é a luz fornecida por uma lâmpada ou um conjunto de LEDs por trás da tela.

Portanto, telas de LCD possuem uma luz constante, onde a intensidade varia de acordo com o bloqueio da luz que brilha através do painel frontal. Sendo assim, estes displays podem ser lidos em ambientes de pouca luminosidade, além de possuir uma alta taxa de atualização, o que possibilita respostas rápidas aos comandos, facilitando a interação.

Além disso, esses displays, em dispositivos de leitura híbridos, proporcionam a visualização de milhões de cores e, de uma maneira geral, possuem uma boa resolução de tela, proporcionando nitidez e riqueza de detalhes. Apesar da maioria das telas LCD possuir um ângulo de visão relativamente pequeno, já existem modelos, como o IPS (InPlane Switching) que possuem ângulos de visão maiores, mais brilho e resolução e quantidade de cores ainda maiores - displays utilizados no iPad, da americana Apple, por exemplo (Apple, 2015; Brandrick, 2010; Mod, 2010; Pctechguide, 2015).
Porém, a leitura neste tipo de tela não é favorável em locais onde a luz do ambiente é muito clara, devido ao brilho na superfície do display (Patrick, 2010). Além disso, por possuir iluminação própria, os dispositivos equipados com telas LCD podem causar fadiga ocular (devido à emissão constante de luz) e acabam consumindo mais energia, resultando em uma menor autonomia de bateria. Todas estas restrições acabam por influenciar na mobilidade do usuário e limitando o seu uso a determinados ambientes, fator que pode condicionar alguns aspectos do projeto gráfico da interface, como pode ser visto na Figura 3.

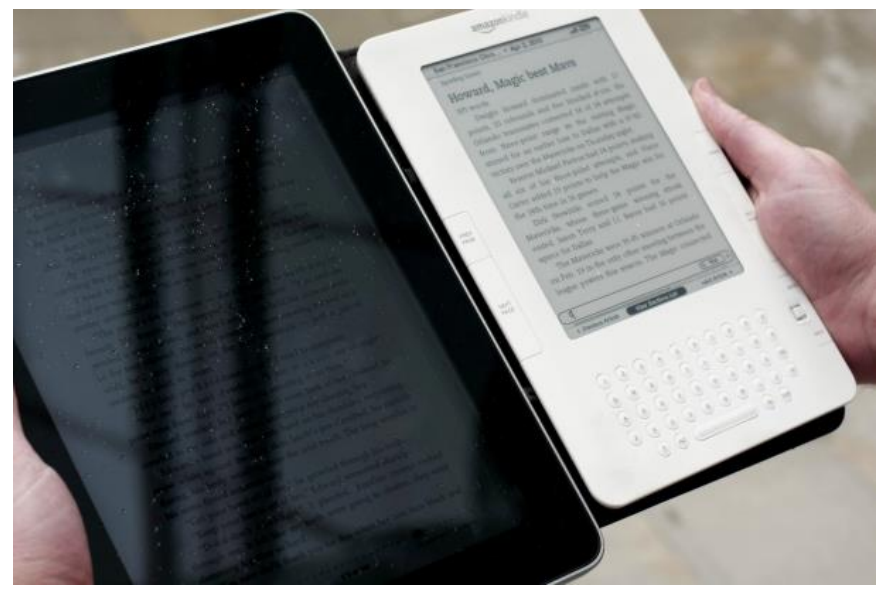

Figura 3: Comparação da visualização de uma tela LCD e um display de papel eletrônico em um ambiente externo. Fonte: David Derrico (2010).

Por possuírem telas sensíveis ao toque (touchscreen), a maioria dos dispositivos híbridos permite - assim como alguns dispositivos dedicados - a navegação por meio da utilização do toque dos dedos, podendo ser multitoque, o que se se refere a uma superfície com a capacidade de reconhecer a presença de dois ou mais pontos de contato.

Segundo Stevens (2011), as telas touchscreen permitem que o usuário literalmente toque no que ele vê, diferentemente da manipulação por meio de mouses e teclados nos computadores de mesa. Nesse sentido, é importante dar atenção ao fato de que a mão humana não é precisa como um mouse. Sendo assim, as áreas passíveis de interação com o usuário devem ser planejadas para isso, possuindo tamanhos adequados. Também, é importante prever áreas que se tornarão obscuras devido ao bloqueio da mão ou regiões que serão de difícil alcance, uma vez que a mão que usuário realizará a interação poderá também estar segurando o dispositivo (Figura 4). 


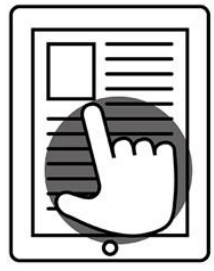

ÁREA OBSCURECIDA PELA MÃO (ESCURA)

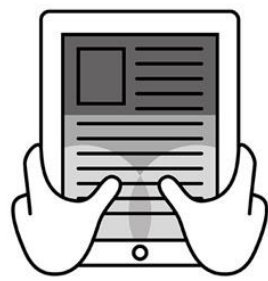

FÁCIL ALCANCE (ÁREA CLARA), DIFÍCIL ALCANCE (ÁREA MÉDIA) MAIS DIFÍCIL ALCANCE (ÁREA ESCURA)
Figura 4: Áreas afetadas pela manipulação por toque. Fonte: autores com base em Stevens (2011).

Além disso, alguns dispositivos híbridos permitem que os elementos gráficos da tela reajam à orientação do suporte no espaço, alterando o leiaute do projeto e até mesmo permitindo a animação de objetos conforme o usuário altera a posição do aparelho (Stevens, 2011).

Em suma, o conjunto das características dos dispositivos híbridos permite ao usuário uma grande interatividade, com ótima qualidade de imagem, respostas precisas e rápidas e uma navegação fácil e intuitiva (Lopes, 2011), proporcionando uma experiência imersiva e satisfatória.

\section{Estudos Recentes Sobre as Tecnologias dos Dispositivos Portáteis de Leitura de Livros Digitais: uma Revisão Sistemática}

De modo a identificar recentes conhecimentos produzidos sobre o tema desta pesquisa, foi realizada uma revisão sistemática de literatura, que seguiu as etapas de Mendes, Silveira e Galvão (2008). Como a revisão sistemática foi parte integrante deste estudo, buscou-se responder à seguinte questão: quais são os estudos mais recentes que tratam sobre as tecnologias dos dispositivos portáteis de leitura de livros digitais?

Inicialmente, foram estabelecidos eixos de termos relevantes ao estudo, sendo eles: o suporte (os dispositivos), o objeto (o livro digital), as diferentes tecnologias e o próprio termo "tecnologia", de modo a limitar a pesquisa apenas aos aspectos tecnológicos. A seguir, foram geradas alternativas de termos relacionados para a definição do algoritmo de pesquisa.

Para a sua definição, as palavras de um mesmo eixo foram ligadas pelo operador "OR", pois eram sinônimos, e os termos de eixos diferentes se conectaram pelo operador "AND". Este então definiu-se assim: "(("e-reader" $O R$ "ereader" $O R$ "electronic reader" OR "tablet") AND ("ebook" OR "e-book") AND ("e-ink" OR "eink" OR "LCD") AND technology)", a ser pesquisado em títulos, resumos e palavras-chave.

Antes de iniciar a pesquisa, definiu-se ainda que só seriam investigados artigos de revistas científicas e conferências, com acesso gratuito via rede UFSC e publicação nos últimos cinco anos à época da revisão (de 2010 a 2015). Por fim, selecionaram-se as bases de dados a serem consultadas. Em função de recorrência na área do conhecimento das Ciências Sociais Aplicadas, escolheram-se as bases Scopus, Web of Science e Science Direct.

Realizando-se a pesquisa e aplicando-se os critérios de filtro, a base Scopus retornou 9 resultados, a Web of Science, 5 resultados e a Science Direct, 63 resultados, totalizando 77 estudos. Os resultados foram então exportados ao gerenciador de referências Mendeley Dekstop, onde foram excluídos aqueles que estivessem duplicados ou incompletos, restando 67 estudos. Após a leitura dos títulos e resumos, excluíram-se os artigos inacessíveis: por não terem acesso gratuito via rede UFSC, estarem em outro idioma senão português, inglês ou espanhol, ou cujas temáticas estavam fora do escopo da pesquisa. Restaram-se então, cinco artigos cujas contribuições iam ao encontro à temática deste estudo. Estes são discutidos a seguir.

\section{Contribuições dos estudos da revisão sistemática}

Como apresentado anteriormente, os atuais dispositivos portáteis de leitura - como o Kindle e o iPad - são compactos e leves, mas possuem diferentes tipos de tecnologia empregados em suas telas. Dessa forma, como afirmam Liesaputra e Wittem (2012), o tamanho, o tipo e a qualidade das diferentes telas afetam diversos aspectos da leitura digital, tais como a velocidade de leitura e o tempo de concentração.

Nesse sentido, diversos autores apontam vantagens e desvantagens de cada tipo de tecnologia. Em seu estudo, Choi et al. (2014) afirmam que o papel eletrônico possui vantagens como o baixo consumo de energia e 0 alto contraste visual. Além disso, por se tratar de uma tecnologia reflexiva - e não transmissiva - a leitura se torna mais agradável aos olhos, qualidade também verificada por Dougherty (2010). Isso se dá em função da ausência de uma fonte luminosa por detrás da tela, justifica o autor, permitindo a visualização em uma grande variação de condições de iluminação, incluindo a luz solar direta. Para ele, tem-se no dispositivo de leitura dedicado uma experiência de leitura similar à do papel, somada à potencialidade de atualização instantânea da informação ali contida.

Por outro lado, Liesaputra e Wittem (2012) apontam que o papel eletrônico requer iluminação extra para leitura em ambientes escuros, além de limitar-se apenas a opções monocromáticas, em concordância com os apontamentos mais recentes de Choi et al. (2014). Para os autores, o uso da monocromia é um problema crítico à apresentação de imagens coloridas, fotografias e gráficos, porém não é significante à leitura textual.

Ainda, o estudo de Liesaputra e Wittem (2012) aponta que as telas de papel eletrônico não são adequadas para apresentar multimídias interativas, em função da sua baixa taxa de atualização, não permitindo ao usuário, por exemplo, alternar entre páginas de maneira ágil.

No que tange a tecnologia empregada nos dispositivos de leitura híbridos (tablets) - as telas de LCD e OLED (organic 
light emitting diode) - Choi et al. (2014) afirmam que estas consomem mais energia e podem causar fadiga visual, em função de sua característica transmissiva, necessitando uma fonte de luz por detrás do suporte, o que resulta em uma baixa legibilidade em ambientes bastante iluminados, como meios externos, por exemplo. Desse modo, conforme os autores, estas tornam-se mais apropriadas a leituras rápidas.

É interessante notar que, no que tange a fadiga visual em telas LCD, Lin, Wu e Cheng (2013) afirmam que esta também é causada por fatores independentes da característica transmissiva da tecnologia. A saber, direção do texto, tamanho da tela e tamanho do caractere, elementos que também influenciam no tempo de leitura e na acurácia da mesma.

Nesse sentido, em seu estudo, Benedetto et al. (2014) realizaram testes comparativos entre diferentes configurações de luminosidade em uma tela LCD e variações no nível de iluminação do ambiente para determinar sua influência na fadiga visual. Após a análise dos resultados, os pesquisadores apontam que não somente a intensidade de luminosidade da tela de um dispositivo pode influenciar no fenômeno, mas também a iluminação do ambiente. Desse modo, ajustes tanto da luminosidade interna dos dispositivos quanto externa (do ambiente) podem resultar na prevenção do cansaço visual, bem como na economia da energia - e por consequência, maior autonomia de uso.

Por fim, Lisaputra e Wittem (2012) apontam que diversas pesquisas têm sido realizadas - em parte por interesses comerciais - no desenvolvimento de dispositivos de leitura que sejam acessíveis, portáteis, duráveis, fáceis de usar, legíveis, confortáveis e com grande capacidade de armazenamento e autonomia de bateria. Desse modo, caminha-se em direção ao desenvolvimento constante das tecnologias, de modo a sobrepor suas atuais fragilidades e consolidar suas qualidades frente aos diferentes tipos de demandas do ambiente digital.

\section{Discussões}

Com o intuito de resumir as vantagens e desvantagens dos diferentes tipos de dispositivos portáteis de leitura apontadas na literatura, elaborou-se o Quadro 1 a partir dos autores pesquisados nas revisões realizadas.

Quadro 1: Vantagens e desvantagens dos dispositivos portáteis de leitura. Fonte: autores a partir da revisão integrativa.

\begin{tabular}{|c|c|c|}
\hline & Vantagens & Desvantagens \\
\hline $\begin{array}{l}\text { Dispositivos } \\
\text { de leitura } \\
\text { dedicados } \\
\text { (e-readers) }\end{array}$ & $\begin{array}{l}\text { Baixo consumo de } \\
\text { energia; } \\
\text { Alto contraste; } \\
\text { Boa visualização sob } \\
\text { luz solar direta; } \\
\text { Leitura mais } \\
\text { confortável aos olhos. }\end{array}$ & $\begin{array}{l}\text { Necessidade de } \\
\text { iluminação extra para } \\
\text { ambientes escuros; } \\
\text { Monocromia; } \\
\text { Baixa taxa de atualização } \\
\text { de tela, sendo } \\
\text { desfavorável à } \\
\text { apresentação de } \\
\text { multimídias interativas. }\end{array}$ \\
\hline Dispositivos & Respostas rápidas aos & Maior consumo de \\
\hline
\end{tabular}

\begin{tabular}{|c|c|c|}
\hline $\begin{array}{l}\text { de leitura } \\
\text { híbridos } \\
\text { (tablets) }\end{array}$ & $\begin{array}{l}\text { comandos, facilitando } \\
\text { a interação; } \\
\text { Renderização de } \\
\text { multimídias (tais como } \\
\text { vídeos, animações, } \\
\text { áudios) e recursos } \\
\text { interativos de modo } \\
\text { efetivo; } \\
\text { Leitura em ambientes } \\
\text { com pouca iluminação; } \\
\text { Visualização de } \\
\text { milhões de cores. }\end{array}$ & $\begin{array}{l}\text { energia; } \\
\text { Podem causar fadiga } \\
\text { visual; } \\
\text { Mesmo ajustados à } \\
\text { máxima luminosidade, há } \\
\text { baixa legibilidade em } \\
\text { ambientes muito } \\
\text { iluminados, como meios } \\
\text { externos. }\end{array}$ \\
\hline
\end{tabular}

A partir do exposto, é possível inferir que a escolha da tecnologia a ser utilizada como suporte ao livro digital depende fortemente do foco principal dessa publicação. Tipicamente, os dispositivos de leitura híbridos (tablets) possuem uma tela mais rápida e capaz de uma taxa de atualização maior, o que os tornam mais adequados à interatividade - utilizando-se principalmente de recursos multimídia e da interação com o usuário.

Por outro lado, os dispositivos de leitura dedicados (ereaders) possibilitam uma melhor legibilidade e maior autonomia de bateria, sendo mais apropriados à leitura contínua, cujo foco se dá na concentração e absorção do conteúdo.

Além disso, a tecnologia, além de já possuir suas próprias limitações e restrições, influencia no tipo de livro digital a ser desenvolvido, que, por sua vez, também determina quais serão as possibilidades de projeto permitidas ao designer.

Sendo assim, em projetos de livros digitais a serem desenvolvidos para dispositivos dedicados (e-readers), as decisões de design tendem a enfatizar as relações de hierarquia e consistência dos elementos que compõem a publicação, uma vez que leiaute, aspectos tipográficos e até mesmo configurações de cor e imagem podem ser alteradas conforme as características do dispositivo, dos aplicativos de leitura ou conforme as preferências do leitor.

Por outro lado, ao se projetar livros digitais para dispositivos híbridos (tablets), o designer tem total controle sobre os mais variados aspectos do projeto gráfico, além da melhor utilização de recursos interativos e multimídia. Entretanto, ao optar por este dispositivo, o projetista pode limitar a compatibilidade da publicação com a multiplicidade de dispositivos (portáteis ou não).

Assim, o Quadro 2 sintetiza a relação entre as características das tecnologias dos dispositivos portáteis de leitura e o design de livros digitais.

Quadro 2: Implicações das diferentes tecnologias de dispositivos portáteis de leitura para o design do livro digital. Fonte: elaborado pelos autores.

\begin{tabular}{l|l|l}
\hline & $\begin{array}{l}\text { Livros digitais } \\
\text { projetados para }\end{array}$ & $\begin{array}{l}\text { Livros digitais } \\
\text { projetados para }\end{array}$ \\
\hline
\end{tabular}




\begin{tabular}{|c|c|c|}
\hline & \begin{tabular}{|l|} 
dispositivos de leitura \\
dedicados (e-readers)
\end{tabular} & $\begin{array}{l}\text { dispositivos de leitura } \\
\text { híbridos (tablets) }\end{array}$ \\
\hline Leiaute & Fluído & Fixo ou fluído \\
\hline $\begin{array}{l}\text { Objetivo do } \\
\text { livro digital }\end{array}$ & $\begin{array}{l}\text { Leitura contínua com } \\
\text { foco na concentração e } \\
\text { absorção do conteúdo. }\end{array}$ & $\begin{array}{l}\text { Leitura rápida, } \\
\text { renderização de } \\
\text { multimídias e interação } \\
\text { com o usuário. }\end{array}$ \\
\hline \multirow{3}{*}{$\begin{array}{l}\text { Decisões de } \\
\text { design }\end{array}$} & Limitadas & Múltiplas \\
\hline & \begin{tabular}{l|} 
Relações de hierarquia \\
e consistência dos \\
elementos tipográficos e \\
compositivos.
\end{tabular} & $\begin{array}{l}\text { Controle sobre os } \\
\text { variados elementos } \\
\text { gráficos (tipografia, cor, } \\
\text { composição) }\end{array}$ \\
\hline & $\begin{array}{l}\text { Uso de mídias estáticas } \\
\text { (texto e imagens). }\end{array}$ & $\begin{array}{l}\text { Uso de mídias dinâmicas } \\
\text { (vídeos e animações). }\end{array}$ \\
\hline Limitações & $\begin{array}{l}\text { Interatividade, } \\
\text { experiência do usuário } \\
\text { e definições de leiaute. }\end{array}$ & $\begin{array}{l}\text { Compatibilidade com a } \\
\text { multiplicidade de } \\
\text { dispositivos. }\end{array}$ \\
\hline Ergonomia & \multicolumn{2}{|c|}{$\begin{array}{l}\text { Em dispositivos touchscreen, é importante observar } \\
\text { as áreas de obstrução pela mão do usuário e as } \\
\text { áreas de fácil, médio e difícil alcance. }\end{array}$} \\
\hline
\end{tabular}

É importante destacar que as implicações apresentadas neste estudo consideram polos distintos de livros digitais, porém, no entremeio existe uma multiplicidade de tipos de livros digitais que resultam na combinação dos pontos expostos, como livros digitais de leiaute fluído para dispositivos de leitura híbridos ou livros de leiaute fixo em formato ePub, cuja compatibilidade de dispositivos é ampla.

Finalmente, de modo a auxiliar os designers na definição de suporte portátil para o livro digital - a partir da coesão dos resultados deste estudo - elaborou-se a matriz apresentada na Figura 5.

Figura 5: Matriz para definição de suporte portátil para o livro digital. Fonte: elaborado pelos autores.

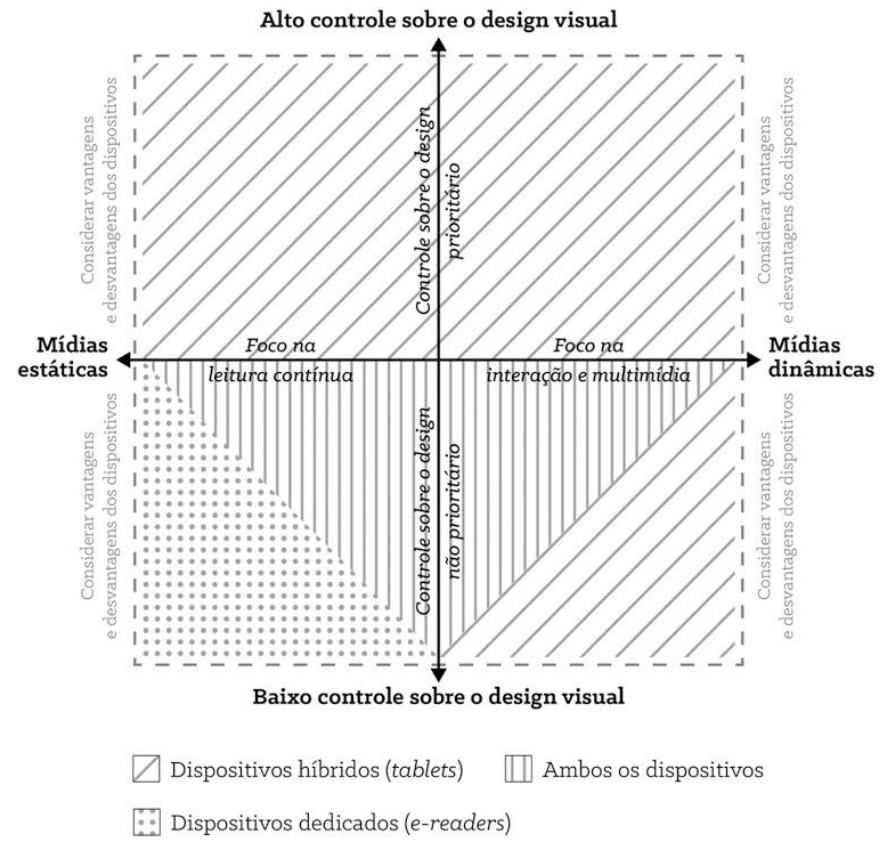

A matriz busca relacionar o grau de controle sobre o design visual (eixo vertical) com o objetivo publicação (eixo horizontal). Dessa forma, na parte superior do eixo vertical, onde o controle sobre o design visual é prioritário no desenvolvimento do livro digital, recomenda-se projetar para dispositivos híbridos (tablets), independente do objetivo da publicação (foco na leitura contínua ou na interação e multimídia) a partir do uso de mídias estáticas ou dinâmicas.

Por outro lado, na parte inferior do eixo vertical, onde o controle sobre o design visual não é prioritário no desenvolvimento do livro digital, o dispositivo recomendado varia de acordo com o objetivo da publicação. Assim, observa-se que a projetação para dispositivos híbridos é recomendada para a maioria dos tipos de livros digitais, uma vez que esses suportes são mais versáteis. De toda forma, existem situações em que os dispositivos dedicados são mais adequados.

Portanto, ressalta-se que na matriz existem zonas de intersecção entre ambos os dispositivos e zonas exclusivas, dependendo das relações estabelecidas entre os eixos. Dessa forma, é importante notar que no momento da definição do suporte, o designer deve também levar em consideração as vantagens e desvantagens de cada tipo de dispositivo, apresentadas anteriormente neste estudo, juntamente do contexto de uso e os futuros usuários/leitores do projeto.

\section{Considerações Finais}

A partir da revisão teórica acerca da evolução histórica dos dispositivos portáteis de leitura de livros digitais, assim como das finalidades e limitações das diferentes tecnologias destes suportes, foi possível identificar a influência das características tecnológicas no design do livro digital. 
Sendo assim, foi possível constatar que os dispositivos de leitura dedicados - representados pelos e-readers proporcionam uma leitura mais confortável aos olhos, apresentando boa visualização em ambientes externos. Por outro lado, suas telas necessitam iluminação em ambientes escuros, são geralmente monocromáticas e apresentam baixa taxa de atualização, o que as tornam desfavoráveis ao processamento de mídias dinâmicas e à interação. Consequentemente, os livros digitais projetados a estes dispositivos tendem a focar-se na leitura contínua e fazer uso de mídias estáticas, permitindo ao projetista menor controle sobre o design visual.

Já os dispositivos de leitura híbridos (tablets e smartphones, por exemplo) permitem respostas rápidas a comandos - 0 que facilita a interação - e possuem telas que possibilitam a visualização de milhões de cores, além do processamento efetivo de mídias dinâmicas e multimídias, mesmo em ambientes com pouca iluminação. No entanto, em função da tecnologia LCD, as telas destes dispositivos podem causar fadiga visual, apresentam maior consumo de energia e possuem baixa legibilidade em ambientes externos. Assim, os livros digitais projetados para estes aparelhos tendem a focarse na leitura rápida, na interação e no uso de multimídias, resultando em um maior controle sobre os aspectos visuais do projeto.

Além destes resultados, constatou-se que, por estar diretamente ligada à tecnologia e ao meio digital, o estudo do livro digital é uma área em desenvolvimento constante e que tanto seus conceitos, quanto formatos ainda mudam rapidamente de acordo com os avanços tecnológicos. Assim, as implicações apresentadas neste estudo não são permanentes e, conforme a tecnologia se desenvolve, podem haver mudanças nos apontamentos trazidos.

Ainda, observa-se que futuros aprimoramentos aos atuais dispositivos portáteis de leitura de livros digitas apontam para evoluções tecnológicas que caminham em direção a telas de papel eletrônico coloridas, bem como aos dispositivos de leitura híbridos com telas de OLED ou até mesmo de LCD estereoscópicas (3D). Somadas a essas evoluções tecnológicas, o designer deve estar atento aos aspectos relacionados ao design de interação e à usabilidade móvel, de modo a criar experiências inovadoras de leitura e interação com o livro digital.

Por fim, além da observância dos fatores tecnológicos, recomenda-se o estudo de estratégias de integração do usuário/leitor na projetação do livro digital, tal como aponta o estudo de Rodrigues (2016), uma vez que o desenvolvimento de produtos digitais deve levar em conta, além da tecnologia, o usuário e seu contexto.

\section{Referências}

Amazon. (2015). Kindle - Released 2012 - Fact Sheet. Disponível em:

<http://www.amazon.com/gp/product/B007HCCOD0/ref=fs_sz>. Acesso em: 22 maio 2015.

Apple. (2015). iPad Air 2. Disponível em: <http://www.apple.com/ipadair-2/>. Acesso em: 15 abr 2015
Benedetto, Simone et al. (2014). Effects of luminance and illuminance on visual fatigue and arousal during digital reading. Computers in Human Behavior, v. 41, n. 0, p. 112-119.

Brandrick, Chris. (2010). iPad: IPS screen technology explained. PCWorld. Disponível em: <http://www.pcworld.com/article/188141/ipad_ips_screen_techn ology_explained.html>. Acesso em 30 abr 2015.

Choi, J. E. et al. (2014). The suitability of gray-scale electronic readers for dermatology journals. Annals of Dermatology, v. 26, n. 6 , p. $700-705$

David Derrico. (2010). E-Ink vs. LCD: What's the difference?. 1 fotografia. Disponível em: <http://www.davidderrico.com/e-inkvs-Icdwhats-the-difference/>. Acesso em: 25 maio 2015.

Dougherty, William C. (2010). E-Readers: Passing Fad or Trend of the Future? The Journal of Academic Librarianship, v. 36, n. 3 , p. 254-256.

Eink. (2015). Technology. Disponível em: $<$ http://www.eink.com/technology.html>. Acesso em: 01 maio 2015.

Electrónica. (2015). Tecnologia LCD. Disponível em: <http://www.electronica-pt.com/index.php/content/view/247/37/>. Acesso em: 04 maio 2015.

Ellington, Kristy. (2012). Create Your Own Interactive Books With Apple's New iBooks Author App. 1 fotografia. Disponível em: $<$ www.popsugar.com/tech/Interactive-iBooks-Author-AppDetails-21408992>. Acesso em: 02 jun 2015.

Farbiarz, Alexandre; Nojima, Vera L. M. dos S. (2003). Um breve olhar sobre a ruptura eletrônica do livro. Belo Horizonte. Disponível em:

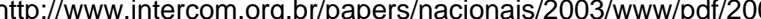
3_NP04_farbiarz.pdf>. Acesso em: 02 maio 2015.

Flatschart, Fabio. (2014). Livro Digital etc. Brasport.

Gall, James E. (2005). Dispelling Five Myths about E-books. Information Technology and Libraries. [S.I.], v. 24, n. 1. Disponível em: <http://www.ala.org/ala/mgrps/divs/lita/ital/volume242005/numbe r1march/gall.pdf>. Acesso em: 01 abr 2015.

Gruszynski, A. (2010). O papel do design na comunicação: uma discussão acerca do livro. Comunicação \& Sociedade. Brasil, ano 31, n. $52 . \quad$ Disponível em: $<$ https://www.metodista.br/revistas/revistasims/index.php/CSO/article/view/1170/1582>. Acesso em: 30 maio 2015.

Liesaputra, Veronica; Witten, lan H. (2012). Realistic electronic books. International Journal of Human-Computer Studies, v. 70, n. 9 , p. $588-610$

Lin, Hsuan; Wu, Fong-Gong; Cheng, Yune-Yu. (2013). Legibility and visual fatigue affected by text direction, screen size and character size on color LCD e-reader. Displays, v. 34, n. 1, p. 49-58.

Lopes, Airton. (2011). A era dos tablets. Info Exame, [S.I.], n. 302. Inovação.

Mendes, Karina Dal Sasso; Silveira, Renata Cristina de Campos Pereira; Galvão, Cristina Maria. (2008). Revisão integrativa: método de pesquisa para a incorporação de evidências na saúde e na enfermagem. Texto contexto - enferm., Florianópolis, v. 17, n. 4. p. 758-764. Disponível em $<$ http://www.scielo.br/scielo.php?script=sci arttext\&pid=S0104$07072008000400018 \&$ Ing $=$ en\&nrm=iso $>$. Acesso em 04 maio 2015.

Olivarez-Giles, N. (2016). Amazon's Kindle Voyage. CEO Jeff Bezos says an 'all-new, top of the line Kindle' is... 1 fotografia. Disponível em: <www.wsj.com/articles/amazon-to-release-new- 
SIGraDi 2016, XX Congress of the Iberoamerican Society of Digital Graphics 9-11, November, 2016 - Buenos Aires, Argentina

kindle-with-rechargeable-protective-case-1459888870>. Acesso em: 12 maio 2016.

Patrick, John. (2010). iPad - Part 1: initial thoughts. Disponível em: $<$ http://www.attitudellc.org/ipad-part-1-initial-thoughts/>. Acesso em 22 maio 2015.

Pctechguide. (2015). IPS - In-Plane Switching LCD Monitors. Disponível em: <http://www.pctechguide.com/flat-paneldisplays/ips-in-plane-switching-Icd-monitors>. Acesso em: 15 abr 2015.

Pinsky, Luciana. (2013). Os editores e o livro digital: o que está sendo feito e pensado em tempos do incunábulo digital. Livro - Revista do Núcleo de Estudos do Livro e da Edição, n.3.

Procópio, Ednei. (2010). O livro na era digital. São Paulo: Giz Editorial.

Rich, Motoko; Stone, Brad. (2008). Turning Page, E-Books Start to Take Hold. The New York Times, [S.I.]. Technology. Disponível em:

<http://www.nytimes.com/2008/12/24/technology/24kindle.html? _ $r=1 \& s c p=1 \& s q=k i n d l e \& s t=c s e>$. Acesso em: 30 maio 2015.

Rodrigues, B. C. de M. (2016). O processo de prototipação no contexto do livro digital de terceira geração. Dissertação (mestrado) - Universidade Federal de Santa Catarina Programa de Pós-Graduação em Design e Expressão Gráfica. Florianópolis, SC.

Royo, Javier. (2008). Fundamentos do design: Design Digital. 1. ed. São Paulo: Rosari.

Santos, Roberta Kerr dos. (2010). A evolução do suporte material, do livro ao e-book: mudanças e impactos ao leitor contemporâneo. Soletras, ano 10, n. 20. São Gonçalo. Disponível em: $<$ http://www.filologia.org.br/soletras/20/02.pdf>. Acesso em 02 maio 2015.

Stevens, Chris. (2011). Designing for the iPad, building applications that sell. Chichester: Wiley.

Strickland, Jonathan. (2008). How the Amazon Kindle Works. HowStuffWorks.com. Disponível

em: $<$ http://electronics.howstuffworks.com/gadgets/travel/amazonkindle.htm>. Acesso em: 22 abr 2015.

Wilson, Ruth. (2001). Evolution of Portable Electronic Books. Ariadne, [S.I.], ed. 29.2 Disponível em: <http://www.ariadne.ac.uk/issue29/wilson/>. Acesso em: 30 maio 2015. 